\title{
Urine sodium concentration to predict fluid responsiveness in oliguric ICU patients: a prospective multicenter observational study
}

Matthieu Legrand ${ }^{1,2,3^{*}}$, Brigitte Le Cam ${ }^{1}$, Sébastien Perbet ${ }^{4}$, Claire Roger ${ }^{5,6}$, Michael Darmon ${ }^{7}$, Philippe Guerci ${ }^{8}$, Axelle Ferry ${ }^{1}$, Véronique Maurel', Sabri Soussi ${ }^{1}$, Jean-Michel Constantin ${ }^{4}$, Etienne Gayat ${ }^{1,2,3}$, Jean-Yves Lefrant ${ }^{5,6}$, Marc Leone ${ }^{9}$ and with the support of the AZUREA network

\begin{abstract}
Background: Oliguria is one of the leading triggers of fluid loading in patients in the intensive care unit (ICU). The purpose of this study was to assess the predictive value of urine $\mathrm{Na}^{+}\left(\mathrm{uNa}^{+}\right)$and other routine urine biomarkers for cardiac fluid responsiveness in oliguric ICU patients.

Methods: We conducted a prospective multicenter observational study in five university ICUs. Patients with urine output (UO) $<0.5 \mathrm{ml} / \mathrm{kg} / \mathrm{h}$ for 3 consecutive hours with a mean arterial pressure $>65 \mathrm{mmHg}$ received a fluid challenge. Cardiac fluid responsiveness was defined by an increase in stroke volume $>15 \%$ after fluid challenge. Urine and plasma biochemistry samples were examined before fluid challenge. We examined renal fluid responsiveness (defined as $U O>0.5 \mathrm{ml} / \mathrm{kg} / \mathrm{h}$ for 3 consecutive hours) after fluid challenge as a secondary endpoint.

Results: Fifty-four patients (age $51 \pm 37$ years, Simplified Acute Physiology Score II score $40 \pm 20$ ) were included. Most patients (72\%) were not cardiac responders (CRs), and $50 \%$ were renal responders (RRs) to fluid challenge. Patient characteristics were similar between CRs and cardiac nonresponders. $\mathrm{uNa}^{+}(37 \pm 38 \mathrm{mmol} / \mathrm{L}$ vs $25 \pm$ $75 \mathrm{mmol} / \mathrm{L}, p=0.44)$ and fractional excretion of sodium ( $\left.\mathrm{FENa}^{+}\right)(2.27 \pm 2.5 \%$ vs $2.15 \pm 5.0 \%, p=0.94)$ were not statistically different between those who did and those who did not respond to the fluid challenge. Areas under the receiver operating characteristic (AUROC) curves were 0.51 (95\% Cl 0.35-0.68) and 0.56 (95\% Cl 0.39-0.73) for $\mathrm{UNa}^{+}$and $\mathrm{FENa}^{+}$, respectively. Fractional excretion of urea had an AUROC curve of 0.70 (95\% Cl 0.54-0.86, $p=0.03$ ) for CRs. Baseline UO was higher in RRs than in renal nonresponders $(1.07 \pm 0.78 \mathrm{ml} / \mathrm{kg} / 3 \mathrm{~h}$ vs $0.65 \pm 0.53 \mathrm{ml} / \mathrm{kg} / 3 \mathrm{~h}$, $p=0.01$ ). The AUROC curve for RRs was 0.65 (95\% Cl 0.53-0.78) for $\mathrm{UNa}^{+}$.
\end{abstract}

Conclusions: In the present study, most oliguric patients were not CRs and half were not renal responders to fluid challenge. Routine urinary biomarkers were not predictive of fluid responsiveness in oliguric normotensive ICU patients.

Keywords: Fluid responsiveness, Natriuresis, Urine output, Acute kidney injury, Cardiac output

\footnotetext{
* Correspondence: matthieu.legrand@aphp.fr

${ }^{1}$ AP-HP, GH St-Louis-Lariboisière, Anesthésie, Réanimation et brûlés, Hôpital

St-Louis, Assistance Publique-Hôpitaux de Paris, 1 rue Claude Vellefaux, 75010

Paris, France

UMR INSERM 942, Institut National de la Santé et de la Recherche Médicale

(INSERM), Lariboisière Hospital, Paris, France

Full list of author information is available at the end of the article
} 


\section{Background}

In the intensive care unit (ICU), oliguria is one of the first variables leading to a fluid challenge [1]. Although several physiological parameters may predict fluid responsiveness (e.g., increase in stroke volume after fluid challenge), most cannot be applied in ICU patients because criteria for validity are not met [2]. In addition, measurement of cardiac output is infrequent. As a result, at the bedside, fluid responsiveness remains difficult to assess [3]. In routine practice, oliguria is one of the leading conditions triggering the decision to apply fluid challenge [1]. This probably reflects the belief that oliguria is an accurate marker of hypovolemia.

A positive cumulative fluid balance has been associated with poor outcome, especially in patients with acute kidney injury (AKI) [4]. Hence, there is still a need for markers to predict fluid responsiveness in order to avoid an overload of fluid loading. Low urine $\mathrm{Na}^{+}$concentration $\left(\mathrm{uNa}^{+}\right)$has long been considered a biomarker of a low intravascular volume state [5]. However, many factors may lead to renin-angiotensin-aldosterone system (RAAS) activation or alteration of intrarenal hemodynamics affecting $\mathrm{uNa}^{+}$independently of intravascular volume [6]. However, the predictive value of $\mathrm{uNa}^{+}$has never been assessed in ICU patients. We therefore conducted this study to evaluate the value of $\mathrm{uNa}^{+}$for cardiac fluid responsiveness in normotensive, oliguric ICU patients. We also examined the renal responsiveness (i.e., urine output) after a fluid challenge as a secondary endpoint.

\section{Methods}

Because this study was observational and did not change daily practice, the institutional review board of the University Hospital of Paris North (IRB00003835) approved the present study (protocol 2013/47NICB) and waived the requirement for obtaining written consent. However, the patients' next of kin were systematically orally informed and could refuse patient participation. Moreover, the patients were later, and as soon as possible, systematically informed and could refuse use of their data.

\section{Patient selection}

This study was performed in five university hospital ICUs. Patients were included if they met the following criteria:

1. They met criteria for oliguria, defined by urine output $<0.5 \mathrm{ml} / \mathrm{kg} / \mathrm{h}$ for 3 consecutive hours [7].

2. The administration of a fluid challenge $(500 \mathrm{ml}$ of isotonic crystalloids over 15 minutes) was indicated by the physician in charge.
3. Their mean arterial pressure was $>65 \mathrm{mmHg}$ and without significant change in norepinephrine dose $(<20 \%)$ during the last $3 \mathrm{~h}$.

4. They did not receive diuretics on the day of inclusion.

Physicians were asked to explain the indications for fluid challenge. The exclusion criteria were patients under 18 years old, patients treated with diuretics, patients with stage $3 \mathrm{AKI}$, pregnancy, patients in whom a decision to withhold or withdraw treatment had been made, moribund patients, and patients who refused to participate.

\section{Measurements}

The main endpoint of the study was fluid responsiveness, defined as an increase in stroke volume $>15 \%$ at the end of the fluid challenge. Patients were classified as cardiac responders (CRs) or cardiac nonresponders (CNRs) accordingly. Secondary endpoints included renal fluid responsiveness, defined as a post-fluid challenge urine output $>0.5 \mathrm{ml} / \mathrm{kg} / \mathrm{h}$ for more than $3 \mathrm{~h}$ (fluid renal responders [RRs]). Patient characteristics, Simplified Acute Physiology Score II (SAPS II) at admission, and reasons for ICU admission were recorded. At inclusion (i.e., at the time of oliguria diagnosis; urine output $<0.5 \mathrm{ml} / \mathrm{kg} / \mathrm{h}$ for 3 consecutive hours), we collected blood and urine samples, performed routine laboratory measurements, and recorded urine output during the previous 3 and $6 \mathrm{~h}$.

Baseline serum creatinine (Screat) level was determined from blood samples taken on admission. In cases where the baseline creatinine plasma level or estimated glomerular filtration rate (eGFR) was not available, the baseline creatinine plasma level was estimated by using the Modification of Diet in Renal Disease equation with a normal eGFR value of $75 \mathrm{ml} /$ minute $/ 1.73 \mathrm{~m}^{2}$. New onset of AKI was defined as (1) an increase in Screat level $26.5 \mathrm{~mol} / \mathrm{L}$ within $48 \mathrm{~h}$ or increase in SCreat to 1.5 times baseline $\geq 26 \mu \mathrm{mol} / \mathrm{L}$ or $>50 \%$ compared with baseline value or (2) need for renal replacement therapy (RRT) [8].

\section{Blood and urine analysis}

Urine samples were immediately analyzed in the central laboratory of each participating center for $\mathrm{uNa}^{+}$, urine creatinine concentration, urine urea concentration (uUrea), and potassium concentration. Screat, $\mathrm{Na}^{+}$, potassium, urea, and chloride were measured at the same time, allowing calculation of fractional excretion of sodium $\left(\mathrm{FENa}^{+}\right)$, fractional excretion of urea (FEurea), and urine/plasma creatinine.

\section{Statistical analysis}

Using fluid responsiveness as the main endpoint, we estimated that an area under the receiver operating 
characteristic (AUROC) curve of $\mathrm{uNa}^{+}$would be clinically relevant if the $95 \% \mathrm{CI}$ of its AUROC curve was $>0.75$, corresponding to a good AUROC $[9,10]$. Inclusion of $\geq 40$ patients was therefore necessary to show an AUROC curve of $\mathrm{uNa}^{+}>0.85$ with $95 \% \mathrm{CI}>0.75$ based on an estimation of $50 \%$ of patients being fluid responders.

Categorical variables were compared using a $x^{2}$ test. The marginal association of biomarkers with fluid responsiveness was studied using the Mann-Whitney $U$ test. The AUROC curve to predict fluid responsiveness was built for urine biochemistry biomarkers. We determined the optimal threshold value using the "closest top left" method. All analyses were performed using IBM SPSS Statistics software (IBM, Armonk, NY, USA). All $p$ values were two-tailed, and a $p$ value $<0.05$ was considered significant. Values are expressed as number and percentage or median and interquartile range accordingly.

\section{Results}

\section{Patient selection}

Fifty-four patients were included (age $64 \pm 19$ years, $n=22$ females, SAPS II score $38 \pm 17$ ) between March 2014 and March 2015. The patient features are shown in Table 1. Reasons for ICU admission were sepsis, neurological disorders, acute respiratory failure, and trauma/burns. At inclusion, seven patients (13\%) were being treated with antibiotics.

\section{Fluid challenge}

Stroke volume was measured using calibrated pulse pressure signal analysis $(n=13)$, ultrasound-derived analysis (transesophageal Doppler; $n=17$ ), or echocardiography $(n=24)$. Before fluid challenge, only cardiac output and central venous oxygen saturation were lower in the CRs than in the CNRs (Table 1). Pulse pressure variations were similar in the CRs and the CNRs $(14 \pm 19 \%$ vs $6 \pm 11 \%, p=0.18)$. During the inclusion day, the CRs and the CNRs received $1543 \pm 1415 \mathrm{ml}$ and $2253 \pm$ $2381 \mathrm{ml}$ of fluid, respectively $(p=0.28)$.

\section{Biomarkers to predict fluid responsiveness \\ Cardiac response}

Fifteen patients (27\%) were CRs to the fluid challenge. Baseline urine output $(0.76 \pm 0.90 \mathrm{ml} / \mathrm{kg} / 3 \mathrm{~h}$ vs $0.94 \pm 0.69 \mathrm{ml} / \mathrm{kg} / 3 \mathrm{~h}, p=0.55)$, Urine soidium $\left(\mathrm{uNa}^{+} 37\right.$ $\pm 38 \mathrm{mmol} / \mathrm{L}$ vs $25 \pm 75 \mathrm{mmol} / \mathrm{L}, p=0.88)$, and $\mathrm{FENa}^{+}$ $(2.3 \pm 2.5 \%$ vs $2.2 \pm 5.0 \%, p=0.40)$ were similar in the CRs and the CNRs, corresponding to AUROC curves for predicting fluid responsiveness of 0.51 (95\% CI 0.35-0.68) and 0.56 (95\% CI 0.39-0.73), respectively, for $\mathrm{uNa}^{\mathrm{i}}$ and $\mathrm{FENa}^{+}$(Fig. 1). $\mathrm{uNa}^{+}$ $<20 \mathrm{mmol} / \mathrm{L}$ and $\mathrm{FENa}^{+}<1 \%$ had sensitivities of $40 \%$ and $93 \%$, respectively, and specificities of $61 \%$ and $41 \%$, respectively, to predict the cardiac response. FEurea (17 \pm $17 \%$ vs $26 \pm 16 \%, p=0.036)$ and uUrea $(200 \pm 154 \mathrm{mmol} /$ $\mathrm{L}$ vs $299 \pm 214 \mathrm{mmol} / \mathrm{L}, p=0.04)$ were less in the CRs than in the CNRs (Fig. 2), corresponding to AUROC curves of 0.70 (95\% CI 0.54-0.86, $p=0.03$ ) and 0.68 (95\% CI 0.53-0.84, $p=0.06$ ), respectively (Fig. 2).

\section{Renal response}

Twenty-seven patients (50 \%) were RRs to the fluid challenge. These changes persisted $6 \mathrm{~h}$ after the fluid challenge. Baseline urine output was $1.07 \pm 0.78 \mathrm{ml} / \mathrm{kg} / 3 \mathrm{~h}$ in the RRs and $0.65 \pm 0.53 \mathrm{ml} / \mathrm{kg} / 3 \mathrm{~h}$ in the renal nonresponders $(p=0.01)$. The AUROC curves for predicting renal fluid responsiveness were 0.65 (95\% CI 0.53-0.78) for $\mathrm{uNa}^{+}, 0.57$ (95 \% CI 0.41-0.73) for $\mathrm{FENa}^{+}$, and 0.61 (95 \% CI 0.45-0.77) for FEUrea. Urine output increased to $1.03 \pm 1.67 \mathrm{ml} / \mathrm{kg} / 3 \mathrm{~h}$ in CRs and to $1.81 \pm 1.38 \mathrm{ml} /$ $\mathrm{kg} / 3 \mathrm{~h}$ in CNRs $(p=0.03$ and $p<0.001$, respectively) compared with baseline during the $3 \mathrm{~h}$ after the fluid challenge (Fig. 3).

\section{Outcome}

Twenty-one patients developed AKI, including seven patients (13\%) requiring RRT ( $p>0.05$ between fluid responders and fluid nonresponders). Eleven patients (21\%) died during their ICU stay $(p>0.05$ between CRs and CNRs).

\section{Discussion}

In our study, most patients with transient oliguria did not increase their cardiac output or their urine output after the fluid challenge. Low urine sodium concentration and $\mathrm{FENa}^{+}$were not reliable predictors of fluid responsiveness. Although FEurea and uUrea were different in the CRs and the CNRs, the differences were not clinically relevant for predicting fluid responsiveness.

In routine practice, low urine output often leads to performing fluid challenge in ICU patients. This is based on the hypothesis of a systemic hemodynamic contribution to low renal blood flow and low urine output $[11,12]$. However, physiological grounds exist to consider oliguria a poor marker of hypovolemia or low intravascular volume [6]. Shock, pain, and the perioperative period are associated with alteration of intrarenal hemodynamics $[13,14]$ and activation of the RAAS, leading to antinatriuresis and antidiuresis $[15,16]$. Our study shows that oliguria with low urine $\mathrm{Na}^{+}$concentration in normotensive ICU patients may not reflect hypovolemia in a large proportion of patients. Hence, fluid challenge may not translate into an increase in cardiac output or urine output.

Low $\mathrm{uNa}^{+}$has long been proposed as a biomarker of prerenal failure as well as low intravascular volume status and/or low cardiac output. However, a low urine 
Table 1 Patient characteristics

\begin{tabular}{|c|c|c|c|c|}
\hline Characteristic & All patients $(n=54)$ & Cardiac responders $(n=15)$ & Cardiac nonresponders $(n=39)$ & $p$ Value \\
\hline Age, years & $64(55-73)$ & $66(54-78)$ & $63(54-72)$ & 0.93 \\
\hline Male sex, $n(\%)$ & $32(59)$ & $8(53)$ & $23(59)$ & 0.73 \\
\hline \multicolumn{5}{|l|}{ Comorbidities, n (\%) } \\
\hline COPD & $8(15)$ & $3(20)$ & $5(13)$ & 0.67 \\
\hline Diabetes mellitus & $8(15)$ & $2(13)$ & $6(15)$ & 1.0 \\
\hline Hypertension & $23(42)$ & $7(47)$ & $16(41)$ & 0.76 \\
\hline Heart failure & $8(15)$ & $5(33)$ & $3(8)$ & 0.03 \\
\hline Cancer & $11(20)$ & $4(27)$ & $7(18)$ & 0.47 \\
\hline \multicolumn{5}{|l|}{ Nephrotoxic agents } \\
\hline NSAIDs & $1(2)$ & $0(0)$ & $1(3)$ & 1.0 \\
\hline ACE inhibitors & $2(4)$ & $0(0)$ & $2(5)$ & 1.0 \\
\hline Aminoglycosides & $9(17)$ & $2(13)$ & $7(18)$ & 1.0 \\
\hline Contrast media & $12(22)$ & $16(23)$ & $9(23)$ & 1.0 \\
\hline \multicolumn{5}{|l|}{ Organ failure } \\
\hline Mechanical ventilation, $n(\%)$ & $33(42)$ & $10(67)$ & $23(59)$ & 0.77 \\
\hline SAPS II score & $39(30-48)$ & $38(25-51)$ & $39(30-48)$ & 0.92 \\
\hline Norepinephrine, $n(\%)$ & $17(31)$ & $6(40)$ & $11(28)$ & 0.52 \\
\hline Lactate, $\mathrm{mmol} / \mathrm{L}$ & $1.8(1.3-2.3)$ & $1.9(0.9-2.8)$ & $1.7(1.3-2.2)$ & 0.39 \\
\hline Blood urea nitrogen, $\mathrm{mmol} / \mathrm{L}$ & $12(8-17)$ & $11(7-15)$ & $13(8-18)$ & 0.93 \\
\hline Serum creatinine, $\mu \mathrm{mol} / \mathrm{L}$ & $90(56-124)$ & $117(81-153)$ & 74 (49-99) & 0.22 \\
\hline Bilirubin, mg/L & $7(1-14)$ & $9(5-13)$ & $7(1-13)$ & 1.00 \\
\hline Bicarbonate, $\mathrm{mmol} / \mathrm{L}$ & $25(22-28)$ & $21(17-25)$ & $26(23-29)$ & 0.06 \\
\hline Platelet count, $10^{3} / \mathrm{L}$ & $346(201-491)$ & $207(95-319)$ & $358(215-501)$ & 1.00 \\
\hline Hemoglobin, g/dl & $9.4(8.1-10.7)$ & $10.4(8.4-12.4)$ & $9.1(8.1-10.1)$ & 0.54 \\
\hline Glucose, $\mathrm{mmol} / \mathrm{L}$ & $7.9(7.0-8.8)$ & $7.9(7.1-8.6)$ & $8.0(6.9-9.1)$ & 0.73 \\
\hline \multicolumn{5}{|l|}{ Reason for ICU admission } \\
\hline Sepsis & $14(26)$ & $2(13)$ & $12(31)$ & 0.3 \\
\hline Neuro-ICU & $5(9)$ & $2(13)$ & $3(8)$ & 0.61 \\
\hline Respiratory failure & $13(24)$ & $1(7)$ & $12(31)$ & 0.08 \\
\hline Trauma/hemorrhage & $7(13)$ & $2(13)$ & $5(13)$ & 1.0 \\
\hline Cardiogenic shock & $1(2)$ & $0(0)$ & $1(3)$ & 1.0 \\
\hline Post-cardiac arrest & $4(7)$ & $2(13)$ & $2(5)$ & 0.3 \\
\hline \multicolumn{5}{|l|}{ Hemodynamic status } \\
\hline $\mathrm{SAP}, \mathrm{mmHg}$ & $134(118-150)$ & $112(104-120)$ & $138(126-150)$ & 0.92 \\
\hline MAP, mmHg & $81(71-91)$ & $74(67-81)$ & 87 (79-95) & 0.07 \\
\hline $\mathrm{HR}$, beats/minute & $98(85-111)$ & $98(82-114)$ & $96(81-111)$ & 0.14 \\
\hline $\mathrm{CO}, \mathrm{L} /$ minute & $5.3(2.8-7.8)$ & $4.9(1.7-8.1)$ & $5.6(3.3-7.9)$ & 0.07 \\
\hline $\mathrm{ScvO}_{2}, \%$ & $75(62-88)$ & $66(54-78)$ & $85(75-95)$ & 0.01 \\
\hline $\mathrm{CVP}, \mathrm{mmHg}$ & $8(6-10)$ & $8(7-9)$ & $7(4-10)$ & 0.58 \\
\hline
\end{tabular}

Abbreviations: ICU intensive care unit, COPD chronic obstructive pulmonary disease, CAD coronary artery disease, NSAIDs nonsteroidal anti-inflammatory drugs, $A C E$ angiotensin-converting enzyme, SAPS I/ Simplified Acute Physiology Score II, SAP systolic arterial pressure, MAP mean arterial pressure, HR heart rate, CO cardiac output, CVP central venous pressure, $\mathrm{ScVO}_{2}$ central venous oxygen saturation

Data are expressed as absolute number (percentage) or median (interquartile range) 

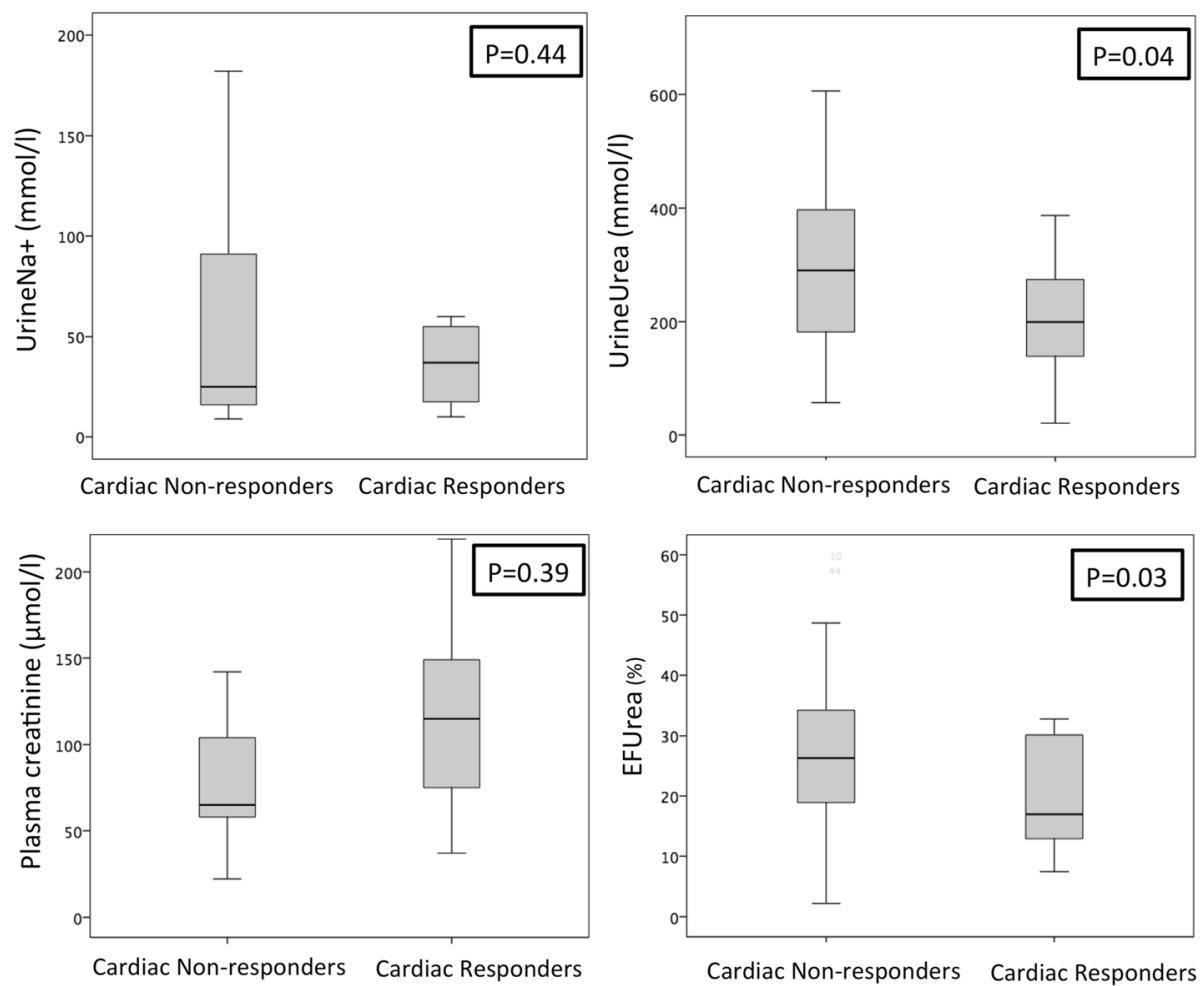

Fig. 1 Box plots representing urine $\mathrm{Na}^{+}$, serum creatinine, urine urea, and fractional excretion of urea (FEurea) at the time of oliguria recognition, according to cardiac fluid responsiveness

$\mathrm{Na}^{+}$concentration is a biomarker of RAAS activation that may be triggered by various factors. Urine biomarkers have previously been shown to inaccurately predict persistent or transient AKI [17]. In a multicenter study, Pons et al. showed that urine biochemistry parameters, including $\mathrm{FENa}^{+}$and FEurea, did not predict the rapid reversibility of AKI [18]. Regulation of urine output and renal $\mathrm{Na}^{+}$handling involves many other factors, including tubular cell function and systemic inflammation $[19,20]$. Therefore, many factors unrelated to intravascular volume and cardiac output may affect urine output and renal $\mathrm{Na}^{+}$handling, including tubular $\mathrm{Na}^{+}$
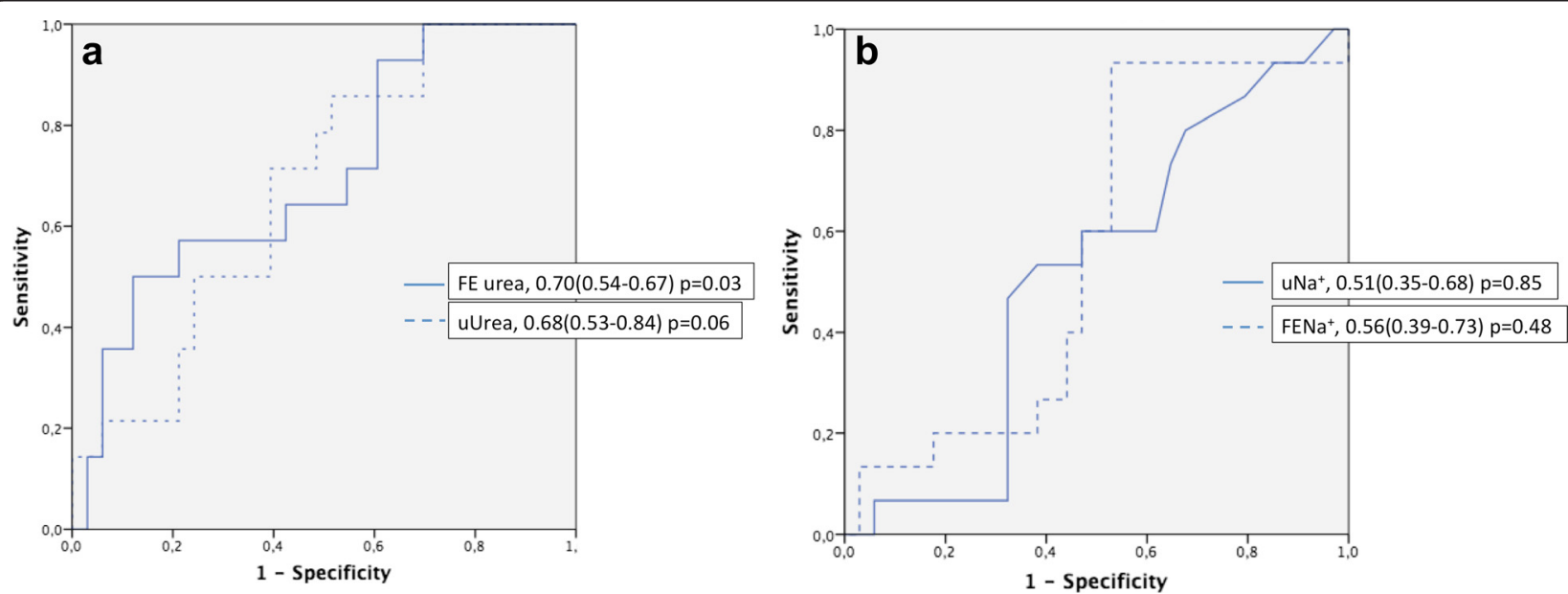

Fig. 2 a Receiver operating characteristic curves of urine urea (uUrea) and fractional excretion of urea (FEurea). b Receiver operating characteristic curves of urine $\mathrm{Na}^{+}\left(\mathrm{uNa}^{+}\right)$and fractional excretion of $\mathrm{Na}^{+}\left(\mathrm{FENa}^{+}\right)$at the time of oliguria recognition to predict cardiac fluid responsiveness. Data are expressed as median $(95 \% \mathrm{Cl})$ 

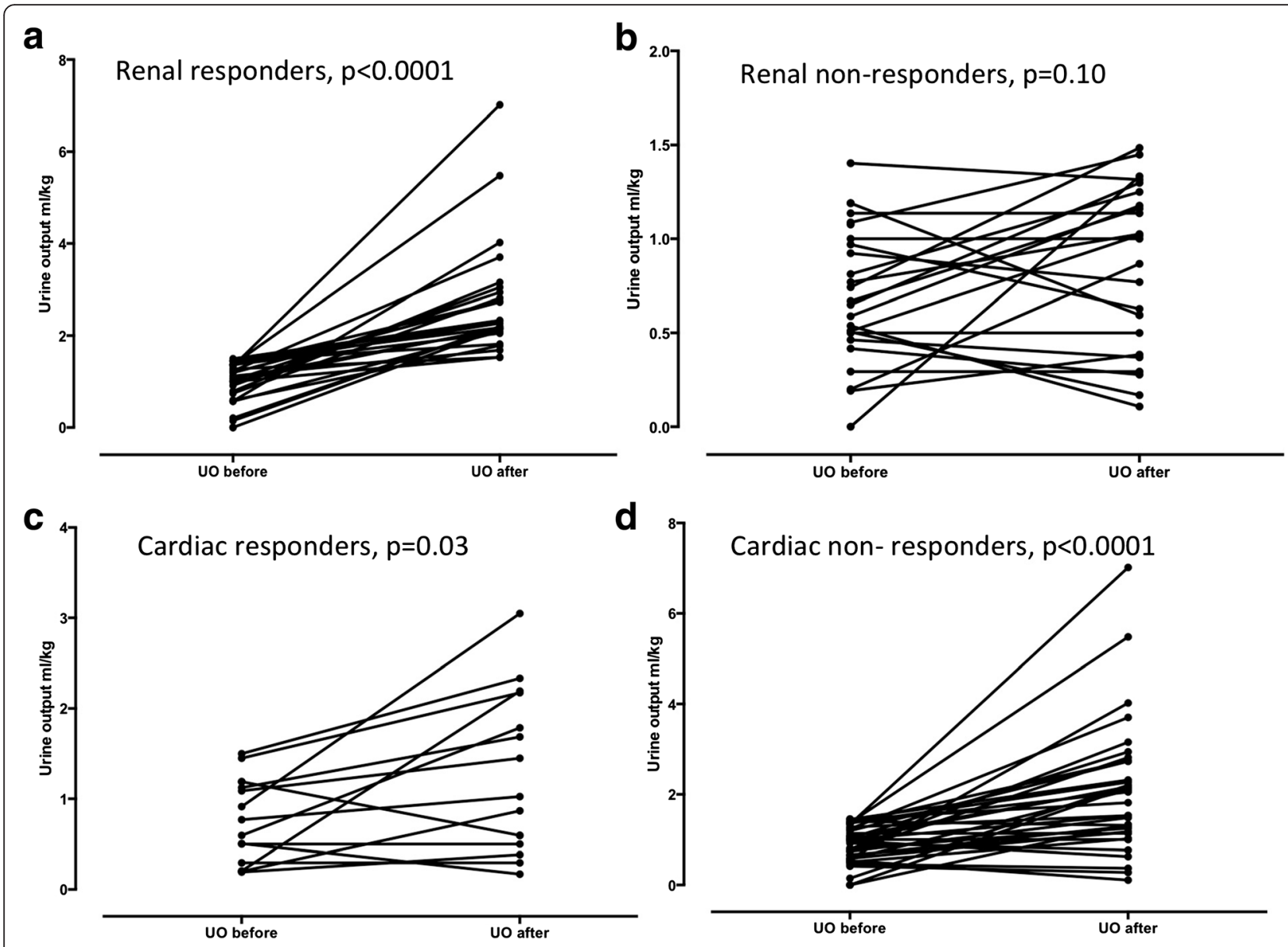

Fig. 3 Evolution of urine output (UO) between $3 \mathrm{~h}$ before and after fluid challenge, respectively, in renal responders (a), renal nonresponders (b), cardiac responders (c), and cardiac nonresponders (d)

channel expression [6]. It therefore remains very difficult to recommend the use of urinary biomarkers to predict fluid responsiveness in critically ill patients. Urine biomarkers may still be indicative of tubular function and renal hemodynamics, but these points were not addressed in the present study. In our study, the influence of renal perfusion pressure on renal hemodynamics was reduced by excluding the patients with mean arterial pressure $<65 \mathrm{mmHg}$. However, urine $\mathrm{Na}^{+}$remained poorly predictive of fluid responsiveness (either cardiac output or renal response) in our patients. Clinicians should therefore rely on other markers of fluid responsiveness when deciding whether to initiate a fluid challenge in patients with oliguria. Nevertheless, we acknowledge that our definition of renal responsiveness was arbitrary, relying on the Kidney Disease: Improving Global Outcomes (commonly referred to as KDIGO [21]) definition with a urine output threshold of $0.5 \mathrm{ml} / \mathrm{kg} / \mathrm{h}$. Some patients showed a relative increase of urine output after the fluid challenge, albeit below this threshold.
Our study has several limitations. First, the sample size was small. However, the sample size was sufficient to detect a good predictive value of the biomarker. This hypothesis can be rejected on the basis of our results. The low rate of inclusion could be explained by several factors. Our patients had to be both oliguric and hemodynamically stabilized, which may have limited the number of patients eligible for inclusion. Second, they had to be off drugs that interact with renal sodium handling (e.g., diuretics). Third, monitoring of cardiac output or an echocardiography-certified physician was required to monitor stroke volume during the fluid challenge. Altogether, these points may limit the external validity of the results. Nevertheless, urine $\mathrm{Na}^{+}$was not strongly associated with fluid responsiveness. A poor predictive value for fluid responsiveness was observed.

Stroke volume was evaluated with different tools. These tools have been used with acceptable accuracy in monitoring stroke volume [2]. Most important, the same monitor was used for each patient, limiting bias. Urine 
biochemistry analyses were not centralized in a single laboratory. This may have generated variability, but it also increased the extrapolation of our results. Norepinephrine infusion was required in some patients, affecting intrarenal hemodynamics. However, Bellomo et al. observed that restoring renal perfusion pressure with norepinephrine decreased renal resistance and increased renal conductance in sepsis [22]. Finally, regarding the AKI definition, we were aware that estimating baseline serum creatinine may have introduced bias into the classification. However, estimation of baseline serum creatinine in ICU patients with no available baseline values remains a challenge, with no consensus on the method of obtaining a surrogate.

\section{Conclusions}

In the present study, most oliguric patients were not cardiac responders and half were not renal responders to fluid challenge. Routine urinary biomarkers were not predictive of fluid responsiveness in oliguric, normotensive ICU patients.

\section{Key messages}

- Most ICU normotensive patients with oliguria do not respond to fluid challenge.

- Urine $\mathrm{Na}^{+}$and urea concentration are not reliable biomarkers of fluid responsiveness in oliguric ICU patients.

- Excessive reliance on oliguria and urine biomarkers may lead to excessive fluid loading with potentially harmful consequences.

\begin{abstract}
Abbreviations
ACE: angiotensin-converting enzyme; AKI: acute kidney injury; CAD: coronary artery disease; CO: cardiac output; COPD: chronic obstructive pulmonary disease; CVP: central venous pressure; eGFR: estimated glomerular filtration rate; $\mathrm{FENa}^{+}$: fractional excretion of sodium; FEurea: fractional excretion of urea; HR: heart rate; ICU: intensive care unit; MAP: mean arterial pressure; NSAID: nonsteroidal anti-inflammatory drug; RAAS: renin-angiotensin-aldosterone system; RRT: renal replacement therapy; SAP: systolic arterial pressure; SAPS II: Simplified Acute Physiology Score II; Screat: serum creatinine; $\mathrm{ScvO}_{2}$ : central venous oxygen saturation; $\mathrm{uNa}^{+}$: urine $\mathrm{Na}^{+}$concentration; UO: urine output; uUrea: urine urea concentration.
\end{abstract}

\section{Competing interests}

$M L$ received lecture fees from Alere and Gilead Sciences, consulting fees from Astellas Pharma and Sphingotec, and a research grant from Baxter. MD received research support from MSD and Astute Medical; speaker's fees from Astellas Pharma, MSD, and Bristol-Myers Squibb; served on the advisory board of Monitor Inc;; and received funds to organize educational meetings from MSD, Astellas Pharma, and Jazz Pharmaceuticals. The other authors. declare that they have no competing interests.

\section{Authors' contributions}

Mleg conceived the study, participated in collection of data; and wrote the first draft of the manuscript. BLC, SP, CR, MD, PG, AF, SS, and VM participated in collection of data and helped to draft the manuscript. EG helped to draft the manuscript and with statistical analysis. JMC, JYL, and Mleg helped with the design of the study, participated in collection of data, and helped to draft the manuscript. All authors read and approved the final manuscript.

\section{Author details}

${ }^{1}$ AP-HP, GH St-Louis-Lariboisière, Anesthésie, Réanimation et brûlés, Hôpital St-Louis, Assistance Publique-Hôpitaux de Paris, 1 rue Claude Vellefaux, 75010 Paris, France. ${ }^{2}$ UMR INSERM 942, Institut National de la Santé et de la Recherche Médicale (INSERM), Lariboisière Hospital, Paris, France. ${ }^{3}$ Université Paris Diderot, F-75475 Paris, France. ${ }^{4}$ Service de Réanimation Adultes et USC, CHU Estaing, Clermont-Ferrand, France. ${ }^{5}$ Service des Réanimations, Pôle Anesthésie Réanimation Douleur Urgence, CHU Nîmes, Place du Professeur Robert Debré, 30029 Nîmes Cedex 9, France. ${ }^{6}$ EA 2992, Faculté de Médecine, Université Montpellier, Nîmes, France. ${ }^{7}$ Service de Réanimation Médicale, Hôpital Nord, CHU Saint-Etienne, EA3065, Faculté de Médecine Jacques Lisfranc, Saint-Etienne, France. ${ }^{8}$ Département d'Anesthésie-Réanimation, CHU Nancy, Vandoeuvre-Lès-Nancy, France. ${ }^{9}$ Service d'Anesthésie-Réanimation, Hôpital Nord, AP-HM, Aix-Marseille Université, Marseille, France.

Received: 18 January 2016 Accepted: 12 May 2016

Published online: 29 May 2016

\section{References}

1. Cecconi M, Hofer C, Teboul JL, Pettila V, Wilkman E, Molnar Z, et al. Fluid challenges in intensive care: the FENICE study: a global inception cohort study. Intensive Care Med. 2015;41:1529-37.

2. Pinsky MR. Functional haemodynamic monitoring. Curr Opin Crit Care. 2014; 20:288-93.

3. Boulain T, Boisrame-Helms J, Ehrmann S, Lascarrou JB, Bouglé A, Chiche A et al. Volume expansion in the first 4 days of shock: a prospective multicentre study in 19 French intensive care units. Intensive Care Med. 2015:41:248-56.

4. Wang N, Jiang L, Zhu B, Wen Y, Xi XM, Beijing Acute Kidney Injury Trial (BAKIT) Workgroup. Fluid balance and mortality in critically ill patients with acute kidney injury: a multicenter prospective epidemiological study. Crit Care. 2015;19:371.

5. Macedo E, Malhotra R, Bouchard J, Wynn SK, Mehta RL. Oliguria is an early predictor of higher mortality in critically ill patients. Kidney Int. 2011;80:760-7.

6. Legrand M, Payen D. Understanding urine output in critically ill patients. Ann Intensive Care. 2011;1:13.

7. Mandelbaum T, Lee J, Scott DJ, Mark RG, Malhotra A, Howell MD, et al. Empirical relationships among oliguria, creatinine, mortality, and renal replacement therapy in the critically ill. Intensive Care Med. 2013;39:414-9.

8. Thomas ME, Blaine C, Dawnay A, Devonald MAJ, Ftouh S, Laing C, et al. The definition of acute kidney injury and its use in practice. Kidney Int. 2015:87:62-73.

9. Ray $P$, Le Manach $Y$, Riou B, Houle $\Pi$ T. Statistical evaluation of a biomarker Anesthesiology. 2010;112:1023-40.

10. Muller L, Toumi M, Bousquet PJ, Riu-Poulenc B, Louart G, Candela D, et al. An increase in aortic blood flow after an infusion of $100 \mathrm{ml}$ colloid over 1 minute can predict fluid responsiveness: the mini-fluid challenge study. Anesthesiology. 2011;115:541-7.

11. Lameire N, Van Biesen W, Vanholder R. Acute renal failure. Lancet. 2005;365:417-30.

12. Payen D, Legrand M. Can we identify prerenal physiology and does it matter? Contrib Nephrol. 2011;174:22-32.

13. Legrand M, Bezemer R, Kandil A, Demirci C, Payen D, Ince C. The role of renal hypoperfusion in development of renal microcirculatory dysfunction in endotoxemic rats. Intensive Care Med. 2011:37:1534-42.

14. Legrand M, Dupuis C, Simon C, Gayat E, Mateo J, Lukaszewicz AC, et al. Association between systemic hemodynamics and septic acute kidney injury in critically ill patients: a retrospective observational study. Crit Care. 2013:17:R278

15. Langenberg C, Wan L, Bagshaw SM, Egi M, May CN, Bellomo R. Urinary biochemistry in experimental septic acute renal failure. Nephrol Dial Transplant. 2006:21:3389-97.

16. Bagshaw SM, Langenberg C, Wan L, May CN, Bellomo R. A systematic review of urinary findings in experimental septic acute renal failure. Crit Care Med. 2007:35:1592-8.

17. Vanmassenhove J, Glorieux G, Hoste E, Dhondt A, Vanholder R, Van Biesen W. Urinary output and fractional excretion of sodium and urea as indicators 
of transient versus intrinsic acute kidney injury during early sepsis. Crit Care. 2013;17:R234.

18. Pons B, Lautrette A, Oziel J, Dellamonica J, Vermesch R, Ezingeard E, et al. Diagnostic accuracy of early urinary index changes in differentiating transient from persistent acute kidney injury in critically ill patients: multicenter cohort study. Crit Care. 2013;17:R56.

19. Olesen ETB, de Seigneux S, Wang G, Lütken SC, Frøkiaer J, Kwon TH, et al. Rapid and segmental specific dysregulation of AQP2, S256-PAQP2 and renal sodium transporters in rats with LPS-induced endotoxaemia. Nephrol Dial Transplant. 2009;24:2338-49.

20. Schmidt C, Höcherl K, Schweda F, Kurtz A, Bucher M. Regulation of renal sodium transporters during severe inflammation. J Am Soc Nephrol. 2007:18:1072-83.

21. Kellum JA, Lameire N; KDIGO AKI Guideline Work Group.Diagnosis, evaluation, and management of acute kidney injury: a KDIGO summary (Part 1). Crit Care. 2013 Feb 4;17(1):204. doi: 10.1186/cc11454.

22. Bellomo R, Kellum JA, Wisniewski SR, Pinsky MR. Effects of norepinephrine on the renal vasculature in normal and endotoxemic dogs. Am J Respir Crit Care Med. 1999;159(4 Pt 1):1186-92

Submit your next manuscript to BioMed Central and we will help you at every step:

- We accept pre-submission inquiries

- Our selector tool helps you to find the most relevant journal

- We provide round the clock customer support

- Convenient online submission

- Thorough peer review

- Inclusion in PubMed and all major indexing services

- Maximum visibility for your research

Submit your manuscript at www.biomedcentral.com/submit
Biomed Central 